\title{
Multiwalled carbon nanotubes incorporated into a miscible blend of poly(phenylenether)/polystyrene - Processing and characterization
}

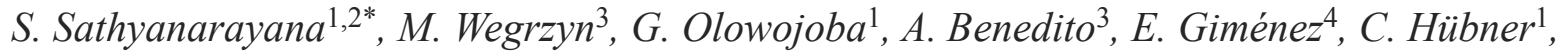 \\ F. Henning ${ }^{1,2}$ \\ ${ }^{1}$ Polymer Engineering Department, Fraunhofer Institute for Chemical Technology ICT, Joseph von Fraunhofer Strasse 7 , \\ 76327 Pfinztal, Germany \\ ${ }^{2}$ Institute of Vehicle System Technology, Chair of Lightweight Technology (FAST), Karlsruhe Institute of Technology \\ (KIT), Rintheimer-Querallee 2, 76131 Karlsruhe, Germany \\ ${ }^{3}$ Instituto Tecnológico del Plástico (AIMPLAS), Calle Gustave Eiffel 4, 46980 Paterna, Spain \\ ${ }^{4}$ Instituto de Tecnología de Materiales. Universidad Politécnica de Valencia, Camino de Vera, 46022 Valencia, Spain
}

Received 8 February 2013; accepted in revised form 11 April 2013

\begin{abstract}
MWCNTs) were incorporated into a miscible blend of polyphenylenether/ polystyrene (PPE/PS) on a twin-screw extruder at a screw speed of $600 \mathrm{rpm}$. The masterbatch obtained was diluted at 400 and $600 \mathrm{rpm}$ to obtain lower MWCNT loadings in PPE/PS. Electron microscopy \& optical microscopy images show very good MWCNT dispersion even at high filler loadings of $4 \mathrm{wt} \%$, but slightly larger agglomerate size fractions are observable at higher screw speeds. While MWCNT addition enhanced the thermal stability of PPE/PS, a small change in glass transition was observed on the composites at different filler concentrations compared to PPE/PS. The specific heat capacity at glass transition decreases considerably until $2 \mathrm{wt} \%$ MWCNT and levels down thereafter for both processing conditions pointing to enhanced filler-matrix interaction at lower loadings. Storage modulus of the nanocomposites was enhanced significantly on MWCNT incorporation with reinforcing effect dropping considerably as a function of temperature, especially at lower filler contents. The modulus and the tensile strength of PPE/PS were only marginally enhanced in spite of excellent MWCNT dispersion in the matrix. Electrical percolation occurs at $0.4 \mathrm{wt} \% \mathrm{MWCNT}$ content, and the electrical conductivity of $0.5 \mathrm{wt} \%$ MWCNT reinforced PPE/PS was close to 12 orders in magnitude higher compared to PPE/PS.
\end{abstract}

Keywords: nanocomposites, carbon nanotubes, twin-screw compounding, characterization and properties

\section{Introduction}

Carbon nanotube (CNT) reinforced polymer nanocomposites have generated significant interest due to the excellent inherent mechanical, electronic and thermal properties of CNTs as reported by Dresselhaus et al. [1]. Reality however indicates otherwise as it has not been possible to achieve the expected commercial success out of these materials owing to the intrinsic tendency of CNTs to agglomerate due to van der Waals forces. The intrinsic cohesive strength of the agglomerates is quite high which makes it difficult to achieve only individually dispersed CNTs in the matrix. Although the extent of initial agglomeration have been demonstrated to be successfully reduced by suitable processing conditions $[2,3]$, desired results especially from the perspective of developing good mechanical properties have been difficult to obtain. The high aspect ratio of CNTs which is expected to enhance the efficiency of reinforcement at extremely lower filler loadings com-

\footnotetext{
*Corresponding author, e-mail: shyam.sathyanarayana@ict.fraunhofer.de (c) BME-PT
} 
pared to its competitors like carbon black, carbon fibers etc. is one reason why CNTs are so attractive. The degree of dispersion of CNTs and the consequent macroscopic behavior is strongly dictated by the choice of the matrix [4, 5], the type of CNT [6-9] and modification of their surface [10-13], and the processing method and associated parameters $[2,3$, 14]. Low filler percolation thresholds have been achieved with CNT reinforcements in epoxy [15, 16], owing to excellent filler dispersion and better compatibility of the CNTs with the resin. Nevertheless, nanocomposites based on thermoplastic resins show more complexities especially when analyzing the effect of processing method on the final properties. Several possibilities exist for the processing of CNT/thermoplastic nanocomposites, but melt mixing is the most interesting from the viewpoint of large-scale industrial processing. CNT based thermoplastic polymer nanocomposites produced by compounding on a twin-screw extruder requires the control of a great number of process variables to tailor the quality of dispersion. Typically, melt compounding must be accompanied by a secondary processing step of either compression molding or injection molding to produce the final part. The low viscosity and minimal influence of shear during compression molding facilitates a suitable environment for the nanoscale re-agglomeration of the previously dispersed agglomerates increasing the composite conductivity $[14,17]$; while decreasing composite mechanical properties. On the other hand, injection molding leads to higher composite bulk resistivity and anisotropy in mechanical characteristics due to two principal reasons: orientation of the CNTs in the direction of flow due to process shear, and the polymer rich skin-core structure due to high temperature differences between the mold wall and the composite melt [18]. Thus, there is a clear relationship between the percolation threshold and the processing methodology.

Several CNT/thermoplastic nanocomposites have been investigated for improvements in mechanical properties, electrical properties or both on single polymers $[4,14,18]$ and polymer blends $[19,20]$. Polymer blends offer an attractive proposition owing to their innovative properties combining the valuable characteristics of the participating polymers. The effectiveness of filler incorporation in a polymer blend is dependent on the wetting parameter and the compatibility of the blends at the molecular level, the former assuming much significance in immiscible blends. The main interest arose in this field after the explanation of the double percolation strategy by Sumita et al. [21] in carbon black filled polymer blends. When the phase in which the filler is localized acts as a continuous phase, the percolation occurs at very low concentration. Double percolation strategy (or co-continuous morphology) has seemingly worked leading to low percolation thresholds especially from the point of electrical conductivity. Multiwalled carbon nanotube (MWCNT) incorporation in polyamide 6 (PA6)/polypropylene (PP) resulted in the selective localization of CNTs in the PA6 phase and a small amount was also found in the interphase between the polymers [20]. In the study reported by Bose et al. [22], nanocomposites based on PA6/acrylonitrile butadiene styrene (ABS) were prepared by melt mixing and a preferential localization of CNTs was observed on the PA6 phase while a few were found to be bridging the two phases. Several other blend systems filled with CNTs such as polycarbonate (PC)/polyethylene (PE) [19], poly ( $\varepsilon$-caprolactone)/polylactide (PCL/PLA) [23], polyamide (PA)/ethyl acetate (EA) [24], PP/ABS [25], polyethylene terephthalate (PET)/polyvinylidene fluoride (PVDF) [26] etc. have also been investigated. However, incorporating MWCNT into miscible polymer blends is seldom reported and hence we focus our attention on this issue in this work. Polyphenylenether/high impact polystyrene (PPE/ PS) is one of the very few completely miscible polymer blends commercially available. The miscibility at the molecular level is a result of the strong interaction between the phenylene ring of PPE and phenyl ring of PS [27]. Tiwari et al. [28] reported enhanced thermal stability and mechanical properties with the addition of nanoclay onto PPE/PS by melt mixing. In this work, we expect a good compatibility between PPE/PS and MWCNTs, principally due to the presence of phenyl groups on all components and possible hydrogen bonding. Higher PPE loading presents enhanced polarity to the blend [29], and this could be expected to contribute to the increased compatibility of the blend with the MWCNTs leading to good filler dispersion in the matrix.

We report the effect of MWCNTs on the morphology, thermal, mechanical and electrical properties of PPE/PS nanocomposites processed on a lab scale twin-screw extruder in this article. 


\section{Experimental}

\subsection{Materials}

MWCNT grade NC7000 (Nanocyl S.A., Sambreville, Belgium) used in this work was produced by the chemical vapor deposition (CVD) process. It had a carbon purity of $90 \%$, average length of $1.5 \mu \mathrm{m}$, average diameter of $9.5 \mathrm{~nm}$ and surface area of $250-300 \mathrm{~m}^{2} / \mathrm{g}$ according to the suppliers. Noryl ${ }^{\circledR}$ 731, a commercial blend of PPE/PS was used as matrix and was supplied by SABIC Innovative Plastics. It had a melt flow rate $(M V R)$ of $8 \mathrm{~cm}^{3} / 10 \mathrm{~min}$. The polymer was dried for $4 \mathrm{~h}$ at $120^{\circ} \mathrm{C}$ while the MWCNTs were used as-received.

\subsection{Processing of the composites}

PPE/PS-MWCNT nanocomposites were produced with a throughput of $1 \mathrm{~kg} / \mathrm{h}$ on a twin-screw co-rotating laboratory extruder Prism Eurolab 16 (Thermo Fisher Scientific, Waltham, USA) with $D=16 \mathrm{~mm}$ and $L / D=25$. The barrel temperatures were set to $280^{\circ} \mathrm{C}$ while two screw speeds of 400 and $600 \mathrm{rpm}$ were employed. A screw profile with a combination of transporting, kneading and back flow elements was employed. MWCNT was fed to the extruder with a pneumatic feeder (Brabender Technologie GmbH \& Co. AG, Duisburg, Germany) together with polymer pellets through the main hopper at a screw speed of $600 \mathrm{rpm}$ which resulted in a masterbatch of $4.0 \mathrm{wt} \%$ MWCNT content. Nanocomposites with lower MWCNT loadings $(0.5,1,1.5$ and $2 \mathrm{wt} \%$ ) were prepared by masterbatch dilution. The $4 \mathrm{wt} \%$ MWCNT filled masterbatch was re-processed at both screw speeds to produce reference composites. Specific mechanical energy $(S M E)$ is an important parameter in extrusion. It is a measure of the resulting energy going into the compounding per unit mass of the melt from the motor and is given by Equation (1):

$S M E\left[\frac{\mathrm{kWh}}{\mathrm{kg}}\right]=\frac{Q_{\mathrm{rat}} \cdot T \cdot \frac{N_{\text {process }}}{N_{\max }} \cdot \eta}{M}$

where $Q_{\text {rat }}-$ motor rating [kW], $T-\%$ of maximum permissible torque used, $N_{\text {process }}-$ screw speed for the process [rpm], $N_{\max }-$ maximum permissible speed [rpm], $\eta$ - gearbox efficiency [\%] and $M-$ process throughput $[\mathrm{kg} / \mathrm{h}]$.

For measuring and characterization of PPE/PS nanocomposites, plates and bars with varying dimensions (refer section 2.3) were prepared by compres- sion molding in a Collin 6300 press (Dr. Collin $\mathrm{GmbH}$, Ebersberg, Germany) aided by ZYVAX water shield mold release agent (ZYVAX, Ellijay, USA). Processing was based on five-step program with pressures varying from 10 to 210 bars between steps at constant upper and lower plate temperatures of $290^{\circ} \mathrm{C}$.

Injection molding of the extruded composites were carried out with the help of a BOY Spritzgiessautomaten 12A equipment (Dr. Boy GmbH \& Co. KG, Neustadt-Fernthal, Germany) fitted with a CTM12LH mold temperature control to produce composite bars for mechanical testing. The temperatures of the mold and melt were set at 100 and $290^{\circ} \mathrm{C}$ respectively, and the melt was injected into the mold at $100 \mathrm{~mm} / \mathrm{s}$. An injection speed of $10 \mathrm{~mm} / \mathrm{s}$ was also employed to study variations in a few composites.

\subsection{Characterization of the composites}

Scanning electron microscopy (SEM) was carried out using a JEOL JSM-7001F FESEM (JEOL, Tokyo, Japan) on cryofractured compression-molded plates. The samples were coated with Platinum for $20 \mathrm{sec}$ at $40 \mathrm{~mA}$ on a sputter coater. Optical micrographs of the composites were made on thin films of approximately $20 \mu \mathrm{m}$ thickness.

Thermo-gravimetric analysis (TGA) was carried out on TGA Q5000 (TA Instruments, New Castle, USA). Around $15 \mathrm{mg}$ of extruded granulates were heated from 50 to $900^{\circ} \mathrm{C}$ at a heating rate of $20^{\circ} \mathrm{C} / \mathrm{min}$ under air atmosphere. The temperature at which $5 \mathrm{wt} \%$ of the material has been degraded is taken to be the temperature of onset of degradation ( $\left.T_{\text {onset }}\right)$ and is evaluated from the temperature vs $\%$ weight loss curve.

Differential scanning calorimetry (DSC) measurements were carried out on extruded granules (8$10 \mathrm{mg}$ ) using a PYRIS Diamond DSC (Perkin Elmer, Waltham, USA). Samples were heated from 40 to $180^{\circ} \mathrm{C}$ at a heating rate of $10^{\circ} \mathrm{C} / \mathrm{min}$ to remove any thermal history on the material. The sample was then cooled to $40^{\circ} \mathrm{C}$ at the rate of $30^{\circ} \mathrm{C} / \mathrm{min}$. Second heating regime was performed similar to the first heating and these observations were used for interpretations. The glass transition temperature $\left(T_{\mathrm{g}}\right)$ and the change in specific heat capacity $\left(C_{\mathrm{p}}\right)$ at $T_{\mathrm{g}}$ were measured.

Dynamic mechanical behavior of the PPE/PSMWCNT nanocomposites was measured on DMA- 
2980 (TA Instruments, New Castle, USA) with dual cantilever clamp at a vibration frequency of $1 \mathrm{~Hz}$ from 35 to $200^{\circ} \mathrm{C}$ and scan rate of $3{ }^{\circ} \mathrm{C} / \mathrm{min}$. Compression-molded samples $(35 \mathrm{~mm} \times 10 \mathrm{~mm} \times$ $1.95 \mathrm{~mm}$ ) were used for the test.

Electrical volume conductivity of the nanocomposites (at least three samples) were measured on compression molded bars $(60 \mathrm{~mm} \times 10 \mathrm{~mm} \times 2 \mathrm{~mm})$ following the Van der Pauw method with four point contact configuration (ISO 3915) using a Keithley Multimeter DMM 2000 (Keithley Instruments Inc. Cleveland, USA). Silver electrodes were painted on the samples in order to minimize contact resistance. The volume conductivity of PPE/PS matrix (three samples) was measured with the help of a Keithley Electrometer 6517A combined with a Keithley 8009 resistivity test fixture on compression molded plates $(110 \mathrm{~mm} \times 110 \mathrm{~mm} \times 2 \mathrm{~mm})$ owing to the inability to measure range of conductivities using the previously mentioned set up. In addition to these, the volume conductivity of the extruded strand was measured similarly to the methodology adopted on compressed bars. The electrical percolation threshold was estimated using the scaling law which describes the statistical percolation behavior in the vicinity of percolation (Equation (2)):

$\sigma \propto\left(w-w_{\mathrm{c}}\right)^{\mathrm{t}}$

where $\sigma$-experimental volume conductivity for $w \geq w_{\mathrm{c}}, w-$ MWCNT concentration [wt $\%$ ], $w_{\mathrm{c}}-$ critical/percolation MWCNT concentration [wt \%], $t$ - critical exponent governing the dimensionality of the system.

Tensile testing of the injection-molded composites was carried out on at least 5 specimens using an Instron Universal Machine 3343 (1 kN load cell) (Instron Deutschland GmbH, Pfungstadt, Germany). Dumb-bell shaped specimens (4 $\mathrm{mm}$ thick) were tested according to the ASTM D638 standard. The samples were drawn at a crosshead speed of $5 \mathrm{~mm} / \mathrm{min}$ at room temperature. The samples were conditioned for $24 \mathrm{~h}$ at $23^{\circ} \mathrm{C}$ and $50 \% \mathrm{RH}$ before testing.

\section{Results and discussion}

\subsection{Effect of processing parameters on morphology}

MWCNT dispersion in matrix is a complicated mechanism involving the wetting of MWCNT agglomer- ates by the melt, matrix infiltration into the agglomerates subsequently followed by the dispersion of agglomerates by erosion, or rupture (i.e. agglomerate shattering) mechanisms determined by the fragmentation number as reported elsewhere [30]. Though wetting, infiltration and dispersion mechanisms directly contribute to the nature and type of the matrix material and CNT, the nature of processing significantly influences the final morphology of the extruded composite.

Figure 1a shows the variations in the $S M E$ inputs as a function of MWCNT loadings at two different processing speeds. Increasing the processing speed from 400 to $600 \mathrm{rpm}$ augmented the $S M E$ by a factor of approximately 1.5 owing to the increase in the shear stresses applied to the melt. This is quite significant as all the other process parameters remained constant. The $S M E$ for the processing of a PPE/PS-4 wt $\%$ MWCNT masterbatch stood at $0.87 \mathrm{kWh} / \mathrm{kg}$. The other nanocomposites processed by diluting or re-processing masterbatch showed lower $S M E$ 's as a result of initial agglomerate dispersion in the masterbatch. The increase in MWCNT loadings resulted in higher SME values owing to the increase in the viscosity which is a direct function of the filler concentration and its dispersive morphology in the matrix. Improvement in the quality of dispersion with the process condi-
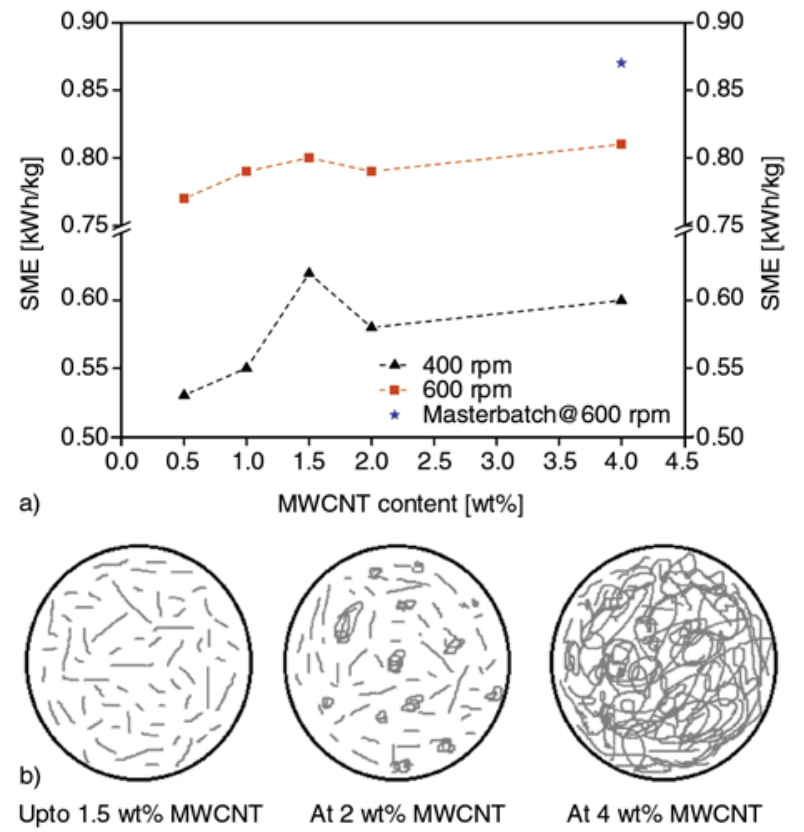

Figure 1. Variation of $S M E$ inputs with MWCNT loadings as a function of processing speed (a) and the sketch showing dispersive morphology at different loadings (b) 
tion owing to de-agglomeration presents an increased surface area for the MWCNTs to interact with the matrix consequently enhancing the viscosity and thus the $S M E$ input. With further increase in MWCNT loading (at $2 \mathrm{wt} \%$ for both processing conditions here), the threshold for optimum filler dispersion could have been exceeded. This represents a scenario where CNT agglomerates behave like large particles which would eventually lower the viscosity than what would be achieved with a perfectly dispersed morphology. Hence, we find a decrease in the $S M E$ at this filler concentration. Further addition of MWCNTs would result in the increase in $S M E$ s principally because of the increased density of agglomerates. This is well illustrated by the sketch in Figure 1b.

Although significant variations in the processing conditions were observed by analyzing the mixing energies, the morphologies of the nanocomposites observed by SEM in Figure $2 \mathrm{a}-2 \mathrm{~d}$ do not show many differences in the qualities of dispersion. It

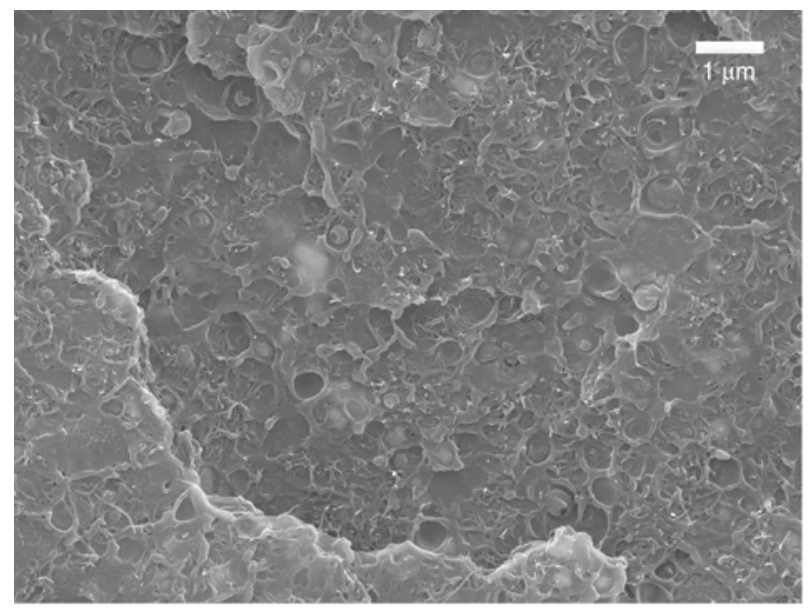

a)

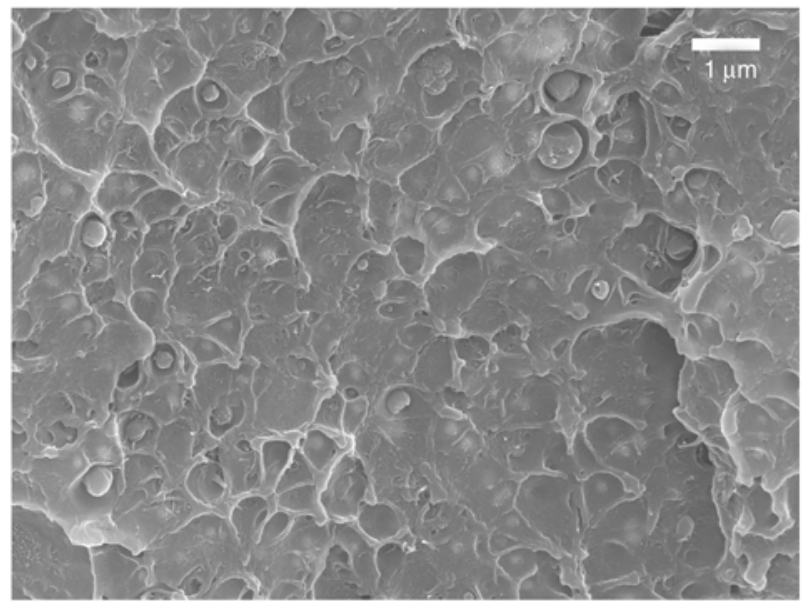

c) was also surprising to note the lack of visible agglomerates even at loadings of $4 \mathrm{wt} \%$ which is quite uncommon when dealing with CNTs. Aromatic group interactions between the matrix and the CNT, together with the polar nature of PPE/PS could have contributed to better filler-matrix compatibility and hence excellent MWCNT dispersion in the matrix. In spite of the high resolution SEM images not showing significant variations in the degree of MWCNT dispersion, it was interesting to note that the optical micrographs of PPE/PS- $0.5 \mathrm{wt} \%$ MWCNT composite processed at $600 \mathrm{rpm}(S M E=0.77 \mathrm{kWh} / \mathrm{kg})$ showed larger agglomerates than those observed on its $400 \mathrm{rpm}(S M E=0.53 \mathrm{kWh} / \mathrm{kg})$ counterpart (Figure 3). This could be due to the shorter residence time for the melt at higher processing speed, which inhibits the efficiency of de-agglomeration of the primary CNT agglomerates.

It is typical of CNT incorporation into an immiscible polymer blend to have a substantial influence on the size of the dispersed phase, this however was

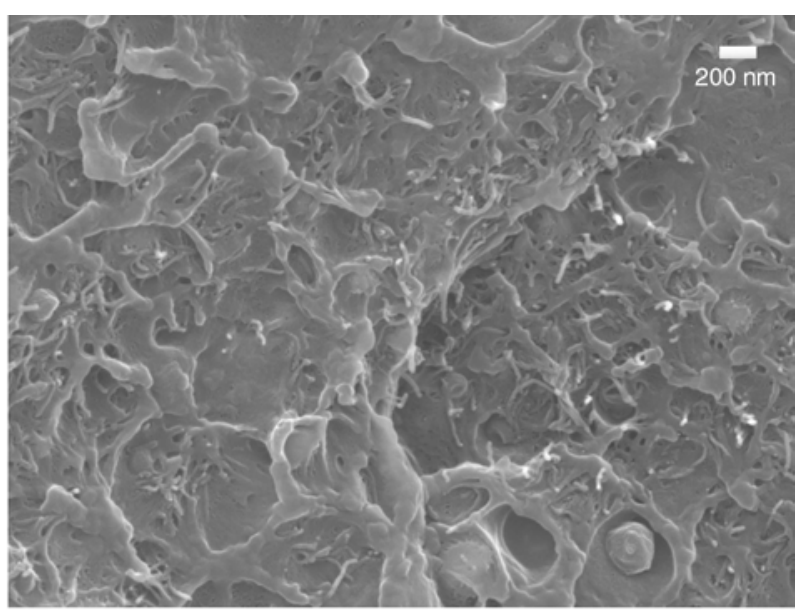

b)

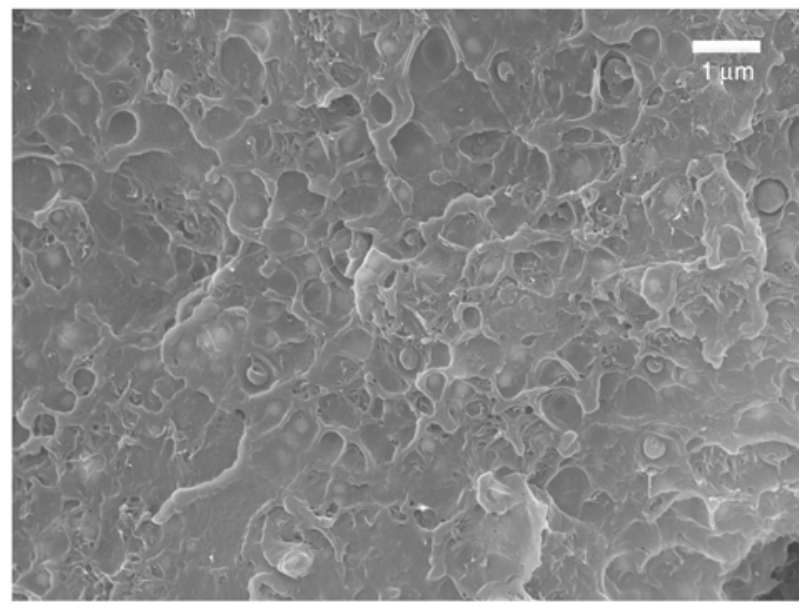

d)

Figure 2. SEM Morphology (a) PPE/PS-4 wt \% MWCNT (Masterbatch), (b) PPE/PS-4 wt\% MWCNT (MasterbatchHigher magnification), (c) PPE/PS-0.5 wt\% MWCNT-600 rpm and (d) PPE/PS-1.5 wt\% MWCNT-600 rpm 


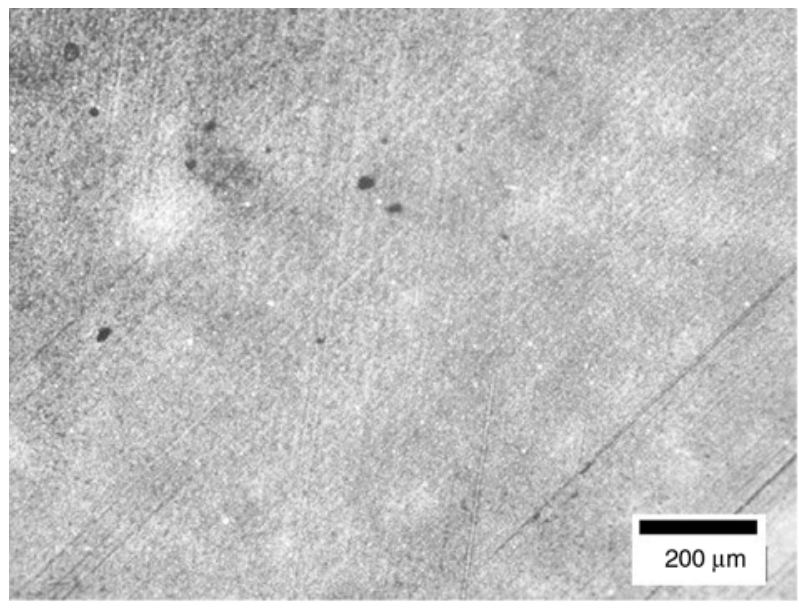

a)

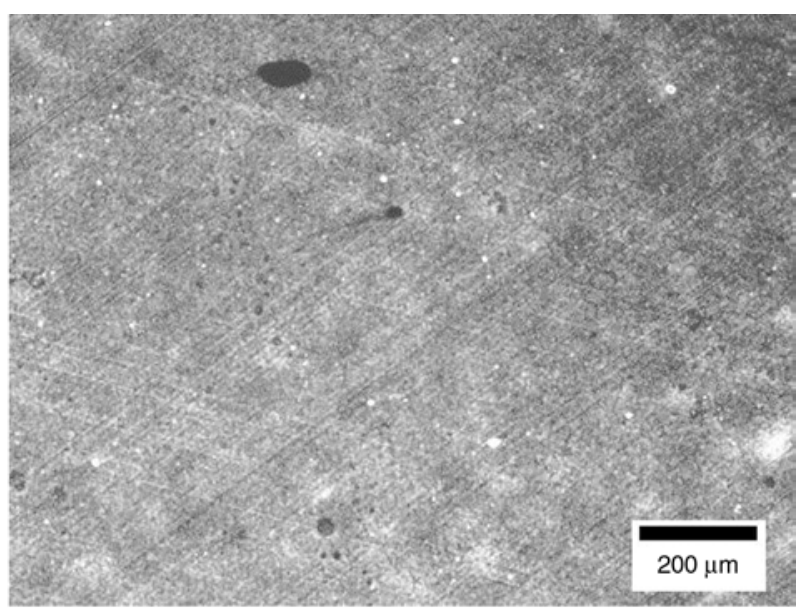

b)

Figure 3. Representative optical micrographs of PPE/PS- $0.5 \mathrm{wt} \%$ MWCNT composites processed at $400 \mathrm{rpm}$ (a) and at $600 \mathrm{rpm}(\mathrm{b})$

not observable in this work as PPE/PS is miscible on a molecular level and hence the SEM images are not presented here.

\subsection{Thermal stability of the nanocomposites}

Figure 4 shows the onset temperature of thermal degradation of the prepared nanocomposites and the pristine matrix. The pure PPE/PS material (PPE/PS-1) and the PPE/PS-4 wt\% MWCNT masterbatch showed $T_{\text {onset }}$ at 417 and $426^{\circ} \mathrm{C}$ respectively. The presence of MWCNTs can lead to the stabilization of PPE/PS matrix, resulting in enhanced thermal stability (about $9^{\circ} \mathrm{C}$ ) of the nanocomposite compared to the pristine polymer. It is well known that CNTs belonging to the $\mathrm{C}_{60}$ family have high electron affinities of about $2.65 \mathrm{eV}$ [31] enabling them to act as efficient radical scavengers. The strong radical accepting capacities interrupt the radical propagation mechanism and hence decrease the rate of

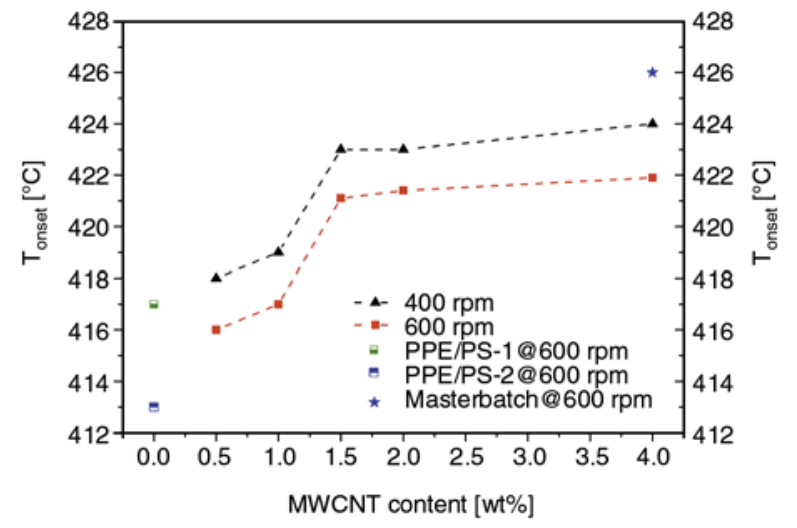

Figure 4. Temperature of onset of degradation $\left(T_{\text {onset }}\right)$ of the matrix and the composites as a function of MWCNT content degradation. This may be the main reason why nanocomposites exhibit better thermal stability compared to the pure polymer. The MWCNTs can effectively act as physical barriers to hinder the transport of volatile decomposed products out of PPE/PS nanocomposites during thermal decomposition.

A $4^{\circ} \mathrm{C}$ decrease in $T_{\text {onset }}$ is observed when the pure $\mathrm{PPE} / \mathrm{PS}$ is processed twice (PPE/PS-2) as compared to PPE/PS-1. The thermal stability of the material suffers in reprocessing as a result of polymer degradation. The same tendency could be expected with nanocomposites which have been processed by diluting the masterbatch. The thermal stability of the samples processed with $400 \mathrm{rpm}$ is slightly better than those processed at $600 \mathrm{rpm}$. The quality of dispersion which was slightly better in the samples processed with $400 \mathrm{rpm}$ enhanced the thermal stability owing to the creation of enhanced MWCNT surface area for interaction with the polymer. To add to this is the contribution of polymer degradation at higher processing speed.

The thermal stability of the composites increased significantly up to $1.5 \mathrm{wt} \%$ MWCNT loading, increasing filler addition beyond this loading does not seem to have a role in regulating the thermal stability of the composite. The filler loading and their respective quality of dispersion would have been the best at $1.5 \mathrm{wt} \%$ MWCNT loading, beyond which agglomeration tendencies of CNTs would have an impact on the composite properties. This correlates well with the observations and discussion on the $S M E$ of the composites from Figure 1. 
The thermal stability of nanocomposites is determined by competitive effects. Whereas MWCNTs act as radical scavengers at low loadings [14] delaying the degradation pattern and enhancing thermal stability, it has also been reported that the enhancement in thermal conductivity on MWCNT addition to the matrix lowers the degradation temperatures [32]. The thermal stability of the nanocomposites depends to a certain extent on the interaction between the phases [33] (which can be presumed to be good here at least from the matrix perspective as PPE/PS is miscible) and the amount of residual metal catalyst in the MWCNTs which was used for their production. The quality of dispersion obtained by process conditions and the effect of polymer degradation also has to be accounted for. The fact that the masterbatch shows higher thermal stability than the diluted nanocomposites at 400 and $600 \mathrm{rpm}$ conveys the combined effect of polymer degradation, dispersion quality and the reinforcing effect of MWCNTs on the thermal stability. It should however be stated that the magnitude of thermal stability increase observed with the PPE/ PS-MWCNT nanocomposites compared to PPE/PS is significantly lower than those observed on PS/ MWCNT nanocomposites [14] where close to $45^{\circ} \mathrm{C}$ variations were observed between pure PS and $2 \mathrm{wt} \%$ MWCNT reinforced nanocomposites depending on process conditions.

\subsection{Glass transition and matrix-filler interactions}

Glass transition measurements provide a qualitative measure of the interaction of the filler with the matrix. Here, glass transition values are reported from the variation of heat capacity from DSC measurements and temperature corresponding to the instance of maximum value of loss modulus $\left(E^{\prime \prime}\right)$ and temperature at maximum tan delta $(\tan \delta)$ inflexion from the DMA measurements. DMA measurements are conducted at frequency range of $1 \mathrm{~Hz}$ compared to those of $10^{-2}-10^{-3} \mathrm{~Hz}$ employed in DSC [34] and this could be the reason for the variation in the magnitude of $T_{\mathrm{g}}$ measured by the two methods.

From the DSC measurements, it can be seen that the $T_{\mathrm{g}}$ of once extruded PPE/PS- 1 stood at $138^{\circ} \mathrm{C}$ while re-processing it (PPE/PS-2) under the same conditions resulted in a slight $T_{\mathrm{g}}$ drop (Figure 5). Polymer degradation with enhanced processing history could be the only reason to explain this $T_{\mathrm{g}}$ drop. Though we speak of thermal degradation here, it is important to be wary of the fact that we had earlier observed a slight enhancement in thermal stability with varying MWCNT loadings into PPE/PS. On the other hand comparing PPE/PS- 1 with the PPE/PS-4 wt $\%$ MWCNT masterbatch, $T_{\mathrm{g}}$ increase of $1.6^{\circ} \mathrm{C}$ is observed in the latter which is principally a result of the filler addition resulting in an interface between the matrix and the filler. Going along this notion, it is worthwhile to refer to the values of PPE/PS-2 for comparison with the composites. MWCNT addition increases the glass transition temperature of the matrix, but the variations are not very significant. The values are slightly higher for nanocomposites processed with $400 \mathrm{rpm}$. After a defined MWCNT loading, $T_{\mathrm{g}}$ suffers slightly.

The principal attribute in a filler-polymer system is the mechanism with which the filler and the polymer contribute to the property fluctuations both on microscopic and macroscopic scales. With CNT reinforcements in polymers three different interactions could be thought of namely polymer-CNT interaction, CNT-CNT interaction and polymer-polymer interaction. At optimum MWCNT concentrations, the two morphologies of fillers would be bridged by a polymer chain if the distance between the neighboring CNT would be less than the actual radius of gyration of the chain. When the MWCNT loading exceeds the threshold for the nanocomposite system in reference, there would be many polymer chains contributing to link the CNT.

Addition of the filler imposes a restriction on the molecular mobility of the polymer in close vicinity

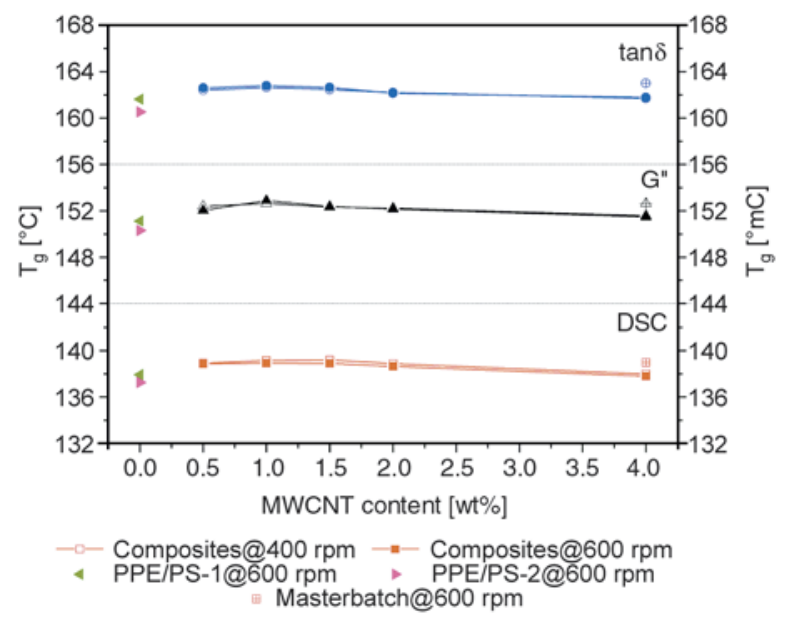

Figure 5. Observation of glass transition $\left(T_{\mathrm{g}}\right)$ by DSC and DMA measurements 
to the filler contributing to the increase in glass transition. $T_{\mathrm{g}}$ of the intermediate layer is dependent upon the thickness of the layer $[35,36]$ and it decreases with approaching distance to the bulk polymer. When the MWCNT concentration is high, the probability for a filler-filler interaction is high resulting in decreasing size of the intermediate layer owing to their overlapping. This could potentially cause an overall reduction in the $T_{\mathrm{g}}$ because of the increase in the free volume for polymer chain mobility.

As MWCNT addition in theory could catalyze polymer degradation [37], the contribution of chain degradation with MWCNT addition and higher speeds of processing should also be taken into account while interpreting these observations. However, it is very difficult to quantify the contribution of degradation and polymer-filler interaction in affecting glass transition. Similar trends of glass transition observations have also been reported on MWCNT filled polystyrene composites [14], but the magnitude of $T_{\mathrm{g}}$ variations was very significant in those observations.

Variation of specific heat $\left(C_{\mathrm{p}}\right)$ during glass transition is a good indicator for the measurement of the level of interaction between the polymer and the filler. It is possible to estimate the fraction of polymer taking part in the glass transition [38]. The fraction of the polymer in direct contact with the filler (tethered onto the filler surface) behaves much different than the bulk and this layer has been regarded as immobile or a rigid amorphous fraction by Litvinov and Speiss [39]. The contribution of this fraction towards glass transition would be minimal as compared to the bulk polymer. With increasing filler contents it is expected of this rigid amorphous fraction to grow in stature thereby reducing the amount of polymer taking part in the glass transition and lowering the specific heat. Figure 6 shows the changes in the specific heat with MWCNT loadings at two different processing speeds. The $C_{\mathrm{p}}$ at glass transition of PPE/PS-2 was lowered from 0.252 to 0.216 and $0.213 \mathrm{~J} /\left(\mathrm{g} \cdot{ }^{\circ} \mathrm{C}\right)$ on addition of $1 \mathrm{wt} \%$ MWCNT at 400 and $600 \mathrm{rpm}$ respectively. Nanocomposites processed at $600 \mathrm{rpm}$ always showed lower $C_{\mathrm{p}}$ values than its $400 \mathrm{rpm}$ counterpart. The fact that the $4 \mathrm{wt} \%$ composites re-processed composites from the masterbatch showing lower $C_{\mathrm{p}}$ values may be attributed to the fact that the variation of $C_{\mathrm{p}}$ is also dependent on the morphology (quality of dispersion) in spite of polymer degrada-

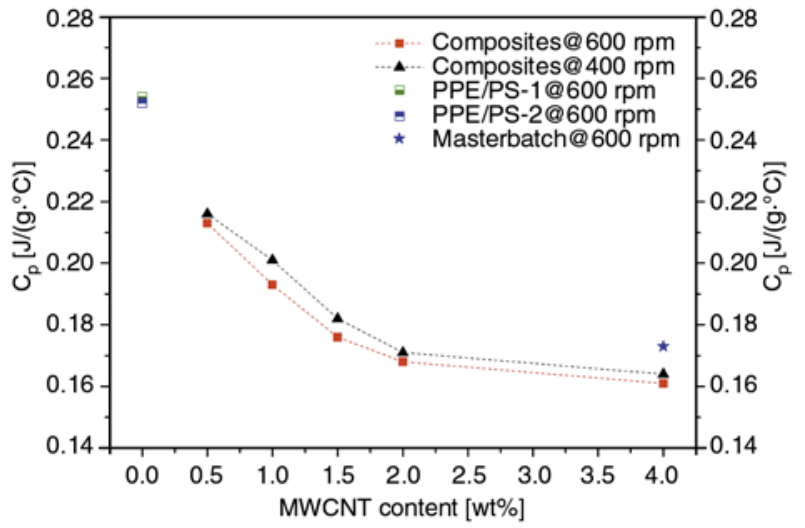

Figure 6. Variation of specific heat at glass transition of the nanocomposites with varying MWCNT loadings at two different processing speeds

tion enhanced processing history. Enhanced surface area of interaction presented by the filler for interaction with the polymer matrix would result in lower $C_{\mathrm{p}}$ values, owing to increased probability of interaction. The rate of $C_{\mathrm{p}}$ decay however slows down on greater than $2 \mathrm{wt} \%$ filler reinforcement which probably indicates the MWCNT threshold. It is also interesting to observe, at higher MWCNT loadings, a decrease in $T_{\mathrm{g}}$ and $C_{\mathrm{p}}$, which is quite uncommon but has however been earlier reported [40, 41].

The area under the $\tan \delta$ curve of DMA measurement is a measure of the amount of polymer taking part in the glass transition according to Brady et al. [38]. Figure 7 shows that the area under the $\tan \delta$ decreases with increase in the filler concentration at the same processing parameters. It is very complicated to evaluate this area for quantitative assessments of polymer-CNT interactions (in terms of evaluating the amount of immobilized polymer etc.).

It is generally accepted that the decrease in the storage modulus $\left(E^{\prime}\right)$ of the composites with increase in

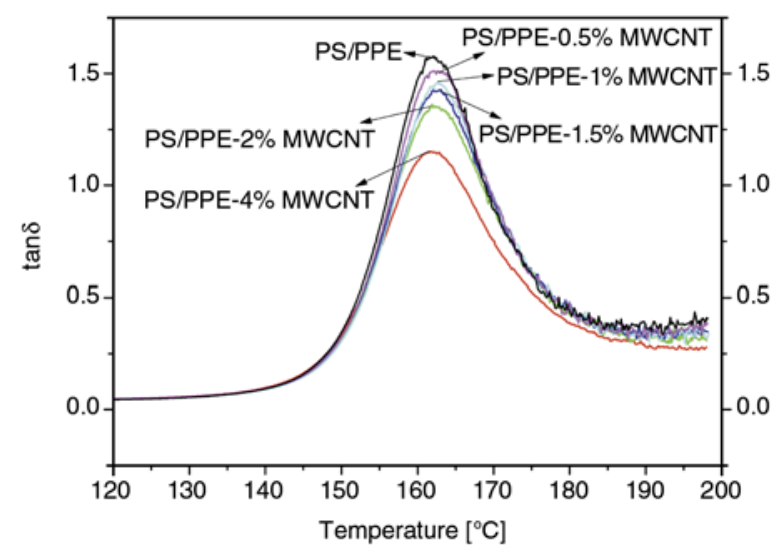

Figure 7. $\tan \delta$ observations as a function of MWCNT content at $600 \mathrm{rpm}$ processing 


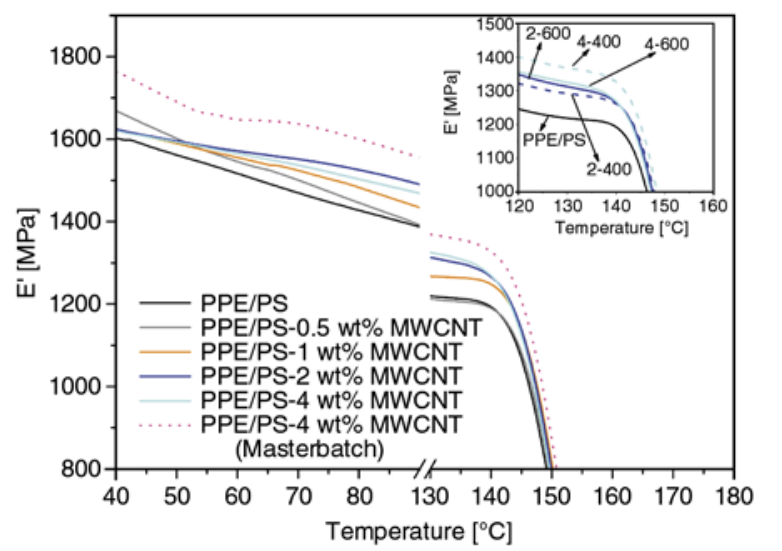

Figure 8. Variation of storage modulus as a function of MWCNT content at $600 \mathrm{rpm}$. Inset: zoomed view of the composites at 400 and $600 \mathrm{rpm}$.

temperature is a result of the co-operative motion of polymer chains leading to energy dissipation. This is among one of the significant observations with our nanocomposite system as well. $E^{\prime}$ of the nanocomposites measured by DMA is shown in Figure 8. The temperature regime has been broken in the axis to illustrate the effects of MWCNT incorporation both in low and high temperature regimes.

Considering the glassy regime, the addition of $4 \mathrm{wt} \%$ MWCNT to the matrix (masterbatch) has resulted in a $10 \%$ increase in the $E^{\prime}$. The modulus of the matrix increased with MWCNT additions primarily due to the inherently higher stiffness of the filler. Increasing addition of MWCNT is generally expected to result in higher modulus, but this need not necessarily be the case always. The composite containing $0.5 \mathrm{wt} \%$ MWCNT exhibited a modulus of $1668 \mathrm{MPa}$ at $40^{\circ} \mathrm{C}$, higher than its counterpart with $4 \mathrm{wt} \%$ CNT loading but less than that of the masterbatch. Also interesting was the significant reduction in the modulus of the masterbatch $\left(E^{\prime}=1763 \mathrm{MPa}\right)$ when it was re-processed $\left(E^{\prime}=1620 \mathrm{MPa}\right)$. These observations point to the fact that the filler loading fraction does not alone suffice for enhancing the modulus of the composites, but the morphology of the composite and the degradation effects also make significant contributions. These observations are slightly contradictory to the extent of $C_{\mathrm{p}}$ change at different MWCNT loadings, but it must be noted that DMA measurements have been made on compression molded samples where potential re-agglomeration of the previously dispersed tubes could have changed the morphology.

When the CNT-CNT distance is less than the radius of gyration of the polymer, the polymer chains tend to bridge the CNTs. With increase in the temperature, the chains lose their stiffness and the morphology is completely revamped and the stability of the polymer-CNT chain decreases and the system is dominated by the polymer-polymer entanglements. At lower CNT loadings this could be a potential cause for the drastic reduction of stiffness with temperature. This is clearly observed where very little difference is noticed between the matrix and the $0.5 \mathrm{wt} \%$ MWCNT reinforced composite. When the filler loading fraction is higher, there is an increased probability of enhanced filler-filler interaction which dominates the aforementioned drawback contributing to enhancement of the mechanical properties; however with the tradeoff of CNT agglomerates acting as elements of stress concentration. At temperatures above the glass transition, very little differences were observed between the modulus of the matrix and the composites.

$E^{\prime}$ of the composites processed with $600 \mathrm{rpm}$ were always higher than their $400 \mathrm{rpm}$ counterparts until 2 wt $\%$ MWCNT loadings (refer inset of Figure 8). At $4 \mathrm{wt} \%$ loading the sample processed with 400 rpm showed higher $E^{\prime}$ which may be attributed to degradation effect in addition to existence of larger primary agglomerates.

\subsection{Mechanical properties of the nanocomposites}

Figure 9 shows the mechanical properties of PPE/ PS and its composites processed with a screw speed of $400 \mathrm{rpm}$ and injection-molded thereafter using an injection speed of $100 \mathrm{~mm} / \mathrm{s}$. The elastic modulus of PPE/PS (2746 MPa) increases by about $2 \%$ on the incorporation of $0.5 \mathrm{wt} \%$ MWCNT. Increasing MWCNT additions further results in improvement in the elastic modulus with $4 \mathrm{wt} \%$ filler incorporation leading to an increase of modulus by $11 \%$. It is expected of inorganic filler to improve the modulus of PPE/PS, and with significantly high aspect ratio of CNTs substantial increase was expected theoretically. A significant reduction in the aspect ratio of the as-received CNTs can be expected as a result of the compounding and the injection molding processes. Also, it might be the case that we do not find individualized CNTs in the matrix (which inherently should have higher modulus), and hence the contribution of the filler to the composite modulus primarily comes from its agglomerates. The agglomerate modulus of the CNTs may not be sig- 


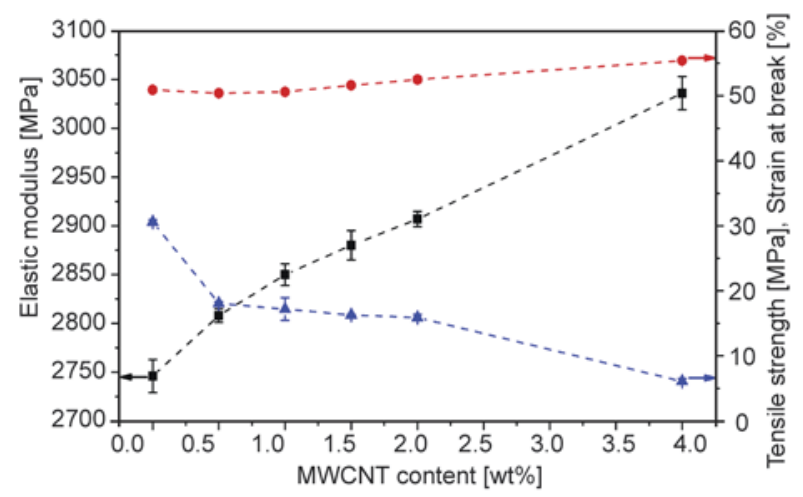

Figure 9. Mechanical properties of the composites (diluted from PPE/PS-4 wt \% MWCNT masterbatch) and $\mathrm{PPE} / \mathrm{PS}$ (processed twice through the extruder) at $400 \mathrm{rpm}$. All samples have identical processing history.

nificantly higher than that of the already stiff PPE/ PS matrix so as to lead to the expected reinforcement. The chance for the dispersed CNTs to exist as entanglements is higher than as a long rigid rod. These reasons could have contributed to lower than expected elastic modulus of the composites in spite of excellent MWCNT dispersion in the matrix (as observed from Figures 2 and 3). Similar observations have been reported earlier in [42-44].

The tensile strength of the composites as observed in Figure 9 happens to be almost identical to the stress at yield and the stress at break. The addition of 0.5 and $1 \mathrm{wt} \%$ MWCNT to PPE/PS resulted in a very minimal drop in the tensile strength of PPE/PS (50.9 MPa), but further MWCNT addition resulted in improved composite tensile strength. The tensile strength of the composite containing $4 \mathrm{wt} \%$ MWCNT was around $9 \%$ higher than that of the matrix. The load bearing capacity of the CNTs is strongly dependent on the level of filler dispersion, matrix-filler interface, aspect ratio of the CNTs and the intrinsic strength of the CNT. In spite of the enhanced surface area available for CNT as a result of good filler dispersion that would facilitate improved polymerfiller interaction, the CNTs used in this work were not functionalized and hence the possibility of a strong interface between the PPE/PS and CNTs is less likely. The aspect ratio of the CNTs in the end composite would not be significant (compared to its as-received form) and the inherent strength of the agglomerated CNTs is obviously not sufficient to create substantial reinforcement. Such reports of very slight improvements or deterioration or tensile strength of polymer-CNT composites are not uncommon [45-47]. It is widely accepted that the addition of CNT results in the lowering of composite ductility. The strain at break of PPE/PS is lowered by $70 \%$ on the addition of $0.5 \mathrm{wt} \%$ MWCNT and by about $400 \%$ on the addition of $4 \mathrm{wt} \%$ MWCNT. Higher CNT loading fraction together with the increasing presence of CNT agglomerates can be attributed to the dramatic lowering of the ductility of the composites.

The mechanical properties of the composites processed at $600 \mathrm{rpm}$ (not presented here) are slightly lower than that of its counterparts processed at $400 \mathrm{rpm}$. The combined effect of slightly poorer quality of macro dispersion of CNT in the composites processed at higher screw speeds (Figure 3), potential polymer degradation, and increased reduction in the length of the CNTs during the compounding process may explain the aforementioned. Concerning the composites processed with a lower injection speed $(10 \mathrm{~mm} / \mathrm{s})$, it was found that the modulus of the composite containing $0.5 \mathrm{wt} \% \mathrm{CNT}$ was $2 \%$ lower than those observed for composites processed with an injection speed of $100 \mathrm{~mm} / \mathrm{s}$ (Figure 9). Similar observations were also found on the composites with higher CNT loading. Even though the probability of CNT aspect ratio reduction would be higher at a higher injection speed, higher modulus of the composites in this case points out the fact that filler orientation (predominant at higher injection speed) plays a key role in affecting the tensile behavior of the composites.

Observation of tensile testing results indicate that it is possible to slightly enhance the mechanical properties of miscible PPE/PS blend by the addition of CNTs with a compromise in composite ductility. This would be a certain value addition to any improved electrical properties of the composite towards the development of a multifunctional composite.

It has to be mentioned here that a direct comparison of the mechanical properties of the composites observed on tensile testing (wherein tested samples were processed by injection molding) to those observed from the DMA measurements (wherein tested samples were processed by compression molding) would not be realistic. The observed properties are influenced by the distribution of CNTs and orientation of flow, anisotropy, crystallinity, etc. which arise due to the nature of the composite shaping process. 


\subsection{Electrical volume conductivity of the nanocomposites}

The electrical conductivity of the compression molded samples and those of the extruded strands are presented in Figure 10. The electrical conductivity of pure PPE/PS was measured to be $1.1 \cdot 10^{-15} \mathrm{~S} / \mathrm{cm}$. Irrespective of the processing speed of the twin-screw extruder, the electrical conductivity of the compression molded PPE/PS- $0.5 \mathrm{wt} \%$ MWCNT composite was 12 orders of magnitude higher than those observed on the pure matrix. Further additions of the filler only contributed to slight improvement in electrical properties. By fitting the measured conductivity data to Equation (2) the percolation concentration $\left(w_{\mathrm{c}}\right)$ and exponent $(t)$ for the composite processed at $600 \mathrm{rpm}$ is observed to be $0.395 \mathrm{wt} \%$ and 1.53 respectively with high a $R^{2}$ value of 0.998 (indicating excellent fit of the regression line to the measured data). The composites processed at $400 \mathrm{rpm}$ shows ' $w_{\mathrm{c}}$ ' and ' $t$ ' values of $0.4 \mathrm{wt} \%$ and 1.62 respectively, also with a very high $R^{2}$ value of 0.996 . Hence, the percolation threshold is not significantly affected by employing varying screw speeds, if the secondary processing operation happens to be compression molding. The determined values of ' $t$ ' as 1.53 and 1.62 for the composites processed with 600 and $400 \mathrm{rpm}$ respectively, agrees well with typically reported ' $t$ ' values in literature between 1.3 and 4 [48], but according to the same literature the physical interpretation of this

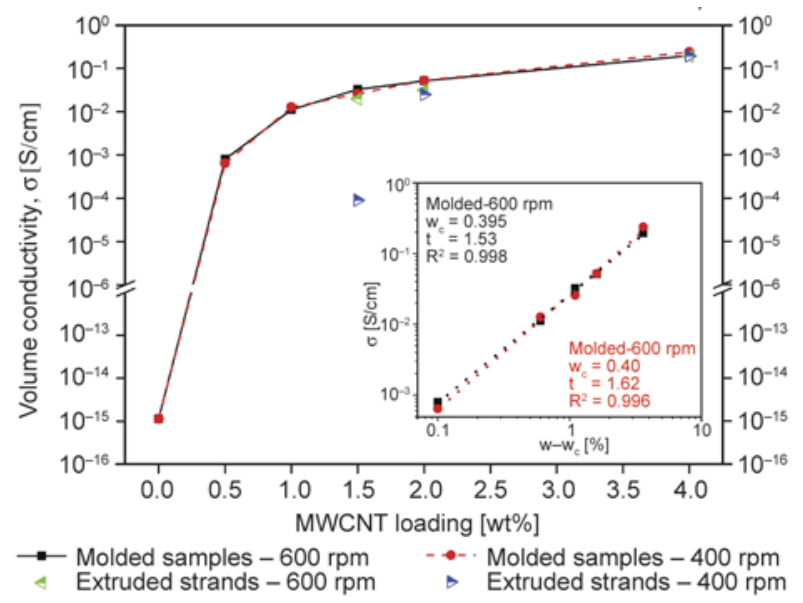

Figure 10. Electrical volume conductivity measurements on extruded strands and compression molded bars of PPE/PS with varying MWCNT loadings at 400 and $600 \mathrm{rpm}$. Inset: log-log plot of conductivity of the compression molded samples as a function of $\left(w-w_{\mathrm{c}}\right)$ with exponent ' $t$ ' and percolation concentration ' $w_{\mathrm{c}}$ ' determined from Equation (2). critical exponent is still controversial. However, it can be interpreted that lower values of ' $t$ ' would mean an abrupt variation in the electrical properties in the vicinity of the percolation, as the magnitude of ' $w-w_{\mathrm{c}}$ ' is less than 1 . According to $[16,25]$, the estimated ' $t$ ' values of the PPE/PS-MWCNT composite system show that electrical percolation is principally governed by the 2-D network of MWCNTs in the matrix.

The compression molded composite samples showed similar electrical conductivity irrespective of the processing speeds at a fixed MWCNT concentration. However, it is interesting to note the variations in the conductivities of the extruded strand. A $1.5 \mathrm{wt} \%$ MWCNT loaded PPE/PS composite processed at $600 \mathrm{rpm}$ exhibited three orders of magnitude lower resistivity than those observed on samples processed at $400 \mathrm{rpm}$. The potential re-agglomeration of the MWCNT as observed in the optical micrographs caused by enhanced SME at $600 \mathrm{rpm}$ could be responsible for creating a conglomerative conductive pathway with comparatively large sized agglomerates and individualized nanotubes compared to processing with $400 \mathrm{rpm}$. The extent of variation decreases at higher MWCNT loadings which may be attributed to enhancement in nanotube content in a defined volume either by increased CNT-CNT contacts or reduced hopping/ tunneling distance. The fact that compression molding reduces the percolation threshold owing to facilitation of nanoscale re-agglomeration at higher temperatures (low viscosity) of pre-dispersed nanotubes (created due to extrusion/melt mixing) explains why the volume resistivities in the extruded strands are higher than those observed on the compression molded bars at lower MWCNT concentrations.

\section{Conclusions}

PPE/PS nanocomposites with varying MWCNT contents were processed on a twin-screw lab scale extruder employing two different processing speeds. Good MWCNT dispersion morphologies were observable on different metric scales from the SEM images and optical micrographs for composites with lower CNT contents. The latter also showed that composites processed at higher screws speeds exhibited larger agglomerate size fractions than those processed at lower screw speeds.

The counter balance between the reinforcing effect of dispersed CNT and the polymer degradation at 
higher processing speeds and at higher filler concentrations determined the thermal stability of the nanocomposites. DSC and dynamic mechanical measurements indicated very little changes in the $T_{\mathrm{g}}$ of the nanocomposites relative to the matrix and higher processing speeds resulted in qualitatively better interfaces. Storage modulus of the nanocomposites increased with MWCNT loading as expected with the $4 \mathrm{wt} \%$ masterbatch showing $10 \%$ enhancement compared to the matrix, while re-processing it diminished its reinforcing capabilities. $E^{\prime}$ was however higher for $0.5 \mathrm{wt} \%$ loading among all the other masterbatch diluted nanocomposites indicative of very high reinforcement capabilities, but with increase in temperature the effect lost its significance.

Tensile testing data showed that the elastic modulus and tensile strength of PPE/PS improved marginally, accompanied with reduction in ductility on MWCNT incorporation. In spite of achieving a good MWCNT dispersion morphology in PPE/PS, substantial improvements in the mechanical properties of the composites were not possible. Reduction in the aspect ratio on processing, inherently weaker mechanical characteristics of the CNT agglomerate fractions (compared to those from highly individualized CNTs with large aspect ratios) that are observed in the matrix, lack of a strong chemical interface and potential polymer degradation could all be attributed as potential reasons for the aforementioned. It was interesting to observe that the orientation effect of CNTs (more predominant at higher injection speed of $100 \mathrm{~mm} / \mathrm{s}$ ) led to slightly higher mechanical characteristics than its counterparts processed with a lower injection speed of $10 \mathrm{~mm} / \mathrm{s}$. Electrical volume conductivity of a $0.5 \mathrm{wt} \%$ MWCNT filled composite samples (compression molded) was twelve orders of magnitude higher compared to pure PPE/PS and no significant differences were observed depending on the processing speed. Electrical percolation was estimated to occur around $0.4 \mathrm{wt} \%$ MWCNT content on the compression molded composites. A favorable environment for the nanoscale re-agglomeration of the dispersed CNTs facilitated by longer holding times at reduced viscosity (during the compression molding process) results in higher electrical conductivity compared to that of the extruded strands at $1.5 \mathrm{wt} \%$ MWCNT loading in PPE/PS. However, this difference diminished with increased MWCNT loadings.

The incorporation of MWCNTs to PPE/PS has led to a significant improvement in the electrical characteristics of the composite at very low filler loading with marginal improvements in thermal stability and mechanical characteristics. Further work on improving the mechanical attributes of the composite is needed for the development of good multifunctional composites.

\section{Acknowledgements}

The research leading to these results has received funding from the European Community's Seventh Framework Programme (FP7-PEOPLE-ITN-2008) under grant agreement number 238363.

\section{References}

[1] Dresselhaus M. S., Dresselhaus G., Charlier J. C., Hernández E.: Electronic, thermal and mechanical properties of carbon nanotubes. Philosophical Transactions of the Royal Society A: Mathematical, Physical and Engineering Sciences, 362, 2065-2098 (2004).

DOI: $10.1098 /$ rsta.2004.1430

[2] Müller M. T., Krause B., Kretzschmar B., Pötschke P.: Influence of feeding conditions in twin-screw extrusion of PP/MWCNT composites on electrical and mechanical properties. Composites Science and Technology, 71, 1535-1542 (2011).

DOI: 10.1016/j.compscitech.2011.06.003

[3] Krause B., Pötschke P., Häußler L.: Influence of small scale melt mixing conditions on electrical resistivity of carbon nanotube-polyamide composites. Composites Science and Technology, 69, 1505-1515 (2009).

DOI: 10.1016/j.compscitech.2008.07.007

[4] Socher R., Krause B., Müller M. T., Boldt R., Pötschke P.: The influence of matrix viscosity on MWCNT dispersion and electrical properties in different thermoplastic nanocomposites. Polymer, 53, 495-504 (2012). DOI: $10.1016 /$ j.polymer.2011.12.019

[5] Ha H., Ha K., Kim S. L.: An empirical equation for electrical resistivity of thermoplastic polymer/multiwalled carbon nanotube composites. Carbon, 48, 1939-1944 (2010).

DOI: 10.1016/j.carbon.2010.01.061

[6] Thostenson E. T., Chou T-W.: Aligned multi-walled carbon nanotube-reinforced composites: Processing and mechanical characterization. Journal of Physics D: Applied Physics, 35, L77-L80 (2002).

DOI: $10.1088 / 0022-3727 / 35 / 16 / 103$ 
[7] López-Manchado M. A., Valentini L., Biagiotti J., Kenny J. M.: Thermal and mechanical properties of single-walled carbon nanotubes-polypropylene composites prepared by melt processing. Carbon, 43, 1499-1505 (2005).

DOI: $10.1016 /$ j.carbon.2005.01.031

[8] Grossiord N., Miltner H. E., Loos J., Meuldijk J., Mele B. V., Koning C. E.: On the crucial role of wetting in the preparation of conductive polystyrene-carbon nanotube composites. Chemistry of Materials, 19, 37873792 (2007).

DOI: $10.1021 / \mathrm{cm} 0629980$

[9] Pötschke P., Bhattacharyya A. R., Janke A.: Melt mixing of polycarbonate with multiwalled carbon nanotubes: Microscopic studies on the state of dispersion. European Polymer Journal, 40, 137-148 (2004). DOI: $10.1016 /$ j.eurpolymj.2003.08.008

[10] Ramanathan T., Liu H., Brinson L. C.: Functionalized SWNT/polymer nanocomposites for dramatic property improvement. Journal of Polymer Science Part B: Polymer Physics, 43, 2269-2279 (2005).

DOI: $10.1002 /$ polb.20510

[11] Camponeschi E., Florkowski B., Vance R., Garrett G., Garmestani H., Tannenbaum R.: Uniform directional alignment of single-walled carbon nanotubes in viscous polymer flow. Langmuir, 22, 1858-1862 (2006). DOI: $10.1021 / 1 \mathrm{a} 052714 \mathrm{z}$

[12] Ma P. C., Tang B. Z., Kim J-K.: Effect of CNT decoration with silver nanoparticles on electrical conductivity of CNT-polymer composite. Carbon, 46, 14971505 (2008).

DOI: $10.1016 /$ j.carbon.2008.06.048

[13] Zou J., Liu L., Chen H., Khondaker S. I., McCullough R. D., Huo Q., Zhai L.: Dispersion of pristine carbon nanotubes using conjugated block copolymers. Advanced Materials, 20, 2055-2060 (2008).

DOI: $10.1002 / \mathrm{adma} .200701995$

[14] Sathyanarayana S., Olowojoba G., Weiss P., Caglar B., Pataki B., Mikonsaari I., Hübner C., Henning F.: Compounding of MWCNTs with PS in a twin-screw extruder with varying process parameters: Morphology, interfacial behavior, thermal stability, rheology, and volume resistivity. Macromolecular Materials and Engineering, 298, 89-105 (2013).

DOI: $10.1002 /$ mame.201200018

[15] Sandler J. K. W., Kirk J. E., Kinloch I. A., Shaffer M. S. P., Windle A. H.: Ultra-low electrical percolation threshold in carbon-nanotube-epoxy composites. Polymer, 44, 5893-5899 (2003).

DOI: 10.1016/S0032-3861(03)00539-1

[16] Hollertz R., Chatterjee S., Gutmann H., Geiger T., Nüesch F. A., Chu B. T. T.: Improvement of toughness and electrical properties of epoxy composites with carbon nanotubes prepared by industrially relevant processes. Nanotechnology, 22, 125702/1-125702/9 (2011).

DOI: $\underline{10.1088 / 0957-4484 / 22 / 12 / 125702}$
[17] Pegel S., Pötschke P., Petzold G., Alig I., Dudkin S. M., Lellinger D.: Dispersion, agglomeration, and network formation of multiwalled carbon nanotubes in polycarbonate melts. Polymer, 49, 974-984 (2008). DOI: $10.1016 /$ j.polymer.2007.12.024

[18] Villmow T., Pegel S., Pötschke P., Wagenknecht U.: Influence of injection molding parameters on the electrical resistivity of polycarbonate filled with multiwalled carbon nanotubes. Composites Science and Technology, 68, 777-789 (2008). DOI: 10.1016/j.compscitech.2007.08.031

[19] Pötschke P., Bhattacharyya A. R., Janke A.: Morphology and electrical resistivity of melt mixed blends of polyethylene and carbon nanotube filled polycarbonate. Polymer, 44, 8061-8069 (2003).

DOI: $10.1016 /$ j.polymer.2003.10.003

[20] Zhang L., Wan C., Zhang Y.: Investigation on the multiwalled carbon nanotubes reinforced polyamide 6/ polypropylene composites. Polymer Engineering and Science, 49, 1909-1917 (2009).

DOI: $10.1002 /$ pen.21428

[21] Sumita M., Sakata S., Asai S., Miyasaka K., Nakagawa H.: Dispersion of fillers and the electrical conductivity of polymer blends filled with carbon black. Polymer Bulletin, 25, 265-271 (1991).

DOI: $10.1007 / \mathrm{BF} 00310802$

[22] Bose S., Bhattarcharya A. R., Bondre A. P., Kulkarni A. R., Pötschke P.: Rheology, electrical conductivity, and the phase behavior of cocontinuous PA6/ABS blends with MWNT: Correlating the aspect ratio of MWNT with the percolation threshold. Journal of Polymer Science Part B: Polymer Physics, 46, 16191631 (2008). DOI: $10.1002 /$ polb.21501

[23] Wu D., Zhang Y., Zhang M., Yu W.: Selective localization of multiwalled carbon nanotubes in poly( $\varepsilon$-caprolactone)/polylactide blend. Biomacromolecules, 10, 417-424 (2009). DOI: $10.1021 / \mathrm{bm} 801183 \mathrm{f}$

[24] Baudouin A-C., Devaux J., Bailly C.: Localization of carbon nanotubes at the interface in blends of polyamide and ethylene-acrylate copolymer. Polymer, 51, 1341-1354 (2010). DOI: $10.1016 /$ j.polymer.2010.01.050

[25] Khare R. A., Bhattacharyya A. R., Kulkarni A. R., Saroop M., Biswas A.: Influence of multiwall carbon nanotubes on morphology and electrical conductivity of PP/ABS blends. Journal of Polymer Science Part B: Polymer Physics, 46, 2286-2295 (2008). DOI: $10.1002 /$ polb. 21560

[26] Wu M., Shaw L. L.: On the improved properties of injection-molded, carbon nanotube-filled PET/PVDF blends. Journal of Power Sources, 136, 37-44 (2004). DOI: 10.1016/j.jpowsour.2004.04.016 
[27] Wellinghoff S. T., Koenig J. L., Baer E.: Spectroscopic examination of chain conformation and bonding in poly(phenylene oxide)-polystyrene blends. Journal of Polymer Science: Polymer Physics Edition, 15, 1913 1925 (1977).

DOI: $10.1002 /$ pol.1977.180151104

[28] Tiwari R. R., Khilar K. C., Natarajan U.: New poly (phenylene oxide)/polystyrene blend nanocomposites with clay: Intercalation, thermal and mechanical properties. Journal of Applied Polymer Science, 108, 1818-1828 (2008).

DOI: $10.1002 /$ app. 27743

[29] Everaert V., Groeninckx G., Pionteck J., Favis B. D., Aerts L., Moldenaers P., Mewis J.: Miscible PS/PPE compounds: An alternative for blend phase morphology studies? Influence of the PPE content on the surface tension of PS/PPE and on the interfacial tension in $\mathrm{PP} /(\mathrm{PS} / \mathrm{PPE})$ and $\mathrm{POM} /(\mathrm{PS} / \mathrm{PPE})$ blends. Polymer, 41, 1011-1025 (2000).

DOI: 10.1016/S0032-3861(99)00239-6

[30] Ottino J. M., DeRoussel P., Hansen S., Khakhar D. V.: Mixing and dispersion of viscous liquids and powdered solids. in 'Advances in chemical engineering' (ed.: Wei J.) Academic Press, San Diego, Vol 25, 105204 (1999).

[31] Krusic P. J., Wassermann E., Keizer P. N., Morton J. R., Preston K. F.: Radical reactions of $\mathrm{C}_{60}$. Science, 254, 1183-1185 (1991).

DOI: $10.1126 /$ science. 254.5035 .1183

[32] Liu Y., Yao Z., Adronov A.: Functionalization of single-walled carbon nanotubes with well-defined polymers by radical coupling. Macromolecules, 38, 11721179 (2005). DOI: $10.1021 / \mathrm{ma} 048273 \mathrm{~s}$

[33] Lizymol P. P., Thomas S.: Thermal behaviour of polymer blends: A comparison of the thermal properties of miscible and immiscible systems. Polymer Degradation and Stability, 41, 59-64 (1993). DOI: 10.1016/0141-3910(93)90061-M

[34] Vatalis A. S., Kanapitsas A., Delides C. G., Pissis P.: Relaxation phenomena and morphology in polymer blends based on polyurethanes investigated by various thermal analysis techniques. Thermochimica Acta, 372, 33-38 (2001). DOI: $10.1016 / \mathrm{S} 0040-6031(01) 00430-0$

[35] Forrest J. A., Dalnoki-Veress K., Stevens J. R., Dutcher J. R.: Effect of free surfaces on the glass transition temperature of thin polymer films. Physical Review Letters, 56, 2002-2005 (1996). DOI: 10.1103/PhysRevLett.77.2002

[36] Forrest J. A., Dalnoki-Veress K., Dutcher J. R.: Interface and chain confinement effects on the glass transition temperature of thin polymer films. Physical Review E, 56, 5705-5716 (1997). DOI: 10.1103/PhysRevE.56.5705
[37] Pötschke P., Bhattacharyya A. R., Janke A., Goering H.: Melt mixing of polycarbonate/multi-wall carbon nanotube composites. Composite Interfaces, 10, 389404 (2003). DOI: $10.1163 / 156855403771953650$

[38] Grady B., Paul A., Peters J. E., Ford W.: Glass transition behavior of single-walled carbon nanotube-polystyrene composites. Macromolecules, 42, 6152-6158 (2009). DOI: $10.1021 / \mathrm{ma900375g}$

[39] Litvinov V. M., Speiss H. W.: ${ }^{2}$ H NMR study of molecular motions in polydimethylsiloxane and its mixtures with aerosils. Die Makromoleculare Chemie, 192, 3005-3019 (1991).

DOI: $10.1002 /$ macp.1991.021921216

[40] Wurm A., Ismail M., Kretzschmar B., Pospiech D., Schick C.: Retarded crystallization in polyamide/layered silicates nanocomposites caused by an immobilized interphase. Macromolecules, 43, 1480-1487 (2010).

DOI: $10.1021 / \mathrm{ma9} 2175 \mathrm{r}$

[41] Castillo F. Y., Socher R., Krause B., Headrick R., Grady B. P., Prada-Silvy R., Pötschke P.: Electrical, mechanical, and glass transition behavior of polycarbonate-based nanocomposites with different multiwalled carbon nanotubes. Polymer, 52, 3835-3845 (2011). DOI: 10.1016/j.polymer.2011.06.018

[42] Mack C., Sathyanarayana S., Weiss P., Mikonsaari I., Hübner C., Henning F., Elsner P.: Twin-screw extrusion of multi walled carbon nanotubes reinforced polycarbonate composites: Investigation of electrical and mechanical properties. IOP Conference Series: Materials Science and Engineering, 40, 012020/1-012020/10 (2012).

DOI: $10.1088 / 1757-899 X / 40 / 1 / 012020$

[43] Sathyanarayana S., Wegrzyn M., Weiss P., Giminéz E., Hübner C., Henning F.: Influence of short glass fiber addition on the morphology and properties of PCMWCNT composites. in 'Proceedings of the $28^{\text {th }}$ Annual Meeting of Polymer Processing Society (PPS28), Pattaya, Thailand', Paper ID: P12012-348 (2012).

[44] Ci L., Bai J.: The reinforcement role of carbon nanotubes in epoxy composites with different matrix stiffness. Composites Science and Technology, 66, 599603 (2006).

DOI: 10.1016/j.compscitech.2005.05.020

[45] Mičušik M., Omastová M., Krupa I., Prokeš J., Pissis P., Logakis E., Pandis C., Pötschke P., Pionteck J.: A comparative study on the electrical and mechanical behaviour of multi-walled carbon nanotube composites prepared by diluting a masterbatch with various types of polypropylenes. Journal of Applied Polymer Science, 113, 2536-2551 (2009).

DOI: 10.1002/app.30418 
[46] Kanagaraj S., Varanda F. R., Zhil’tsova T. V., Oliveira M. S. A., Simões J. A. O.: Mechanical properties of high density polyethylene/carbon nanotube composites. Composites Science and Technology, 67, 30713077 (2007).

DOI: $10.1016 /$ j.compscitech.2007.04.024

[47] Breton Y., Désarmot G., Salvetat J. P., Delpeux S., Sinturel C., Beguin F., Bonnamy S.: Mechanical properties of multiwall carbon nanotubes/epoxy composites: Influence of network morphology. Carbon, 42, $1027-$ 1030 (2004).

DOI: 10.1016/j.carbon.2003.12.026
[48] Bauhofer W., Kovacs J. S.: A review and analysis of electrical percolation in carbon nanotube polymer composites. Composites Science and Technology, 69, 1486-1498 (2009).

DOI: $10.1016 /$ j.compscitech.2008.06.018 